\title{
Gross and histopathological lesions associated with tuberculosis in two sloth bears (Melursus ursinus) in India
}

N. Gowri Menon', K. C. Bipin², P. M. Deepa ${ }^{3}$, R. L. Rathish', M. Pradeep ${ }^{5}$ and A. Sha Arun ${ }^{6}$ Department of Veterinary Epidemiology and Preventive Medicine, College of Veterinary and Animal Sciences, Kerala Veterinary and Animal Sciences University, Pookode, Wayanad, Kerala, India.

Citation: Menon, N. G., Bipin, K. C., Deepa,P. M., Rathish, R. L., Pradeep, M. and Sha Arun, A. 2021. Gross and histopathological lesions associated with tuberculosis in two sloth bears (Melursus ursinus) in India. J. Vet. Anim. Sci. 52(2):161-165.

DOI: https://doi.org/10.51966/jvas.2021.52.2.161-165

Received: 21.12 .2020

Accepted: 25.01.2021

Published: 01.06.2021

\begin{abstract}
Post-mortem examination of two sloth bears which died in Bannerghatta Bear Rescue Centre, Bengaluru, Karnataka, were performed. Both the animals were anorectic and had considerable weight loss before death. Representative lung tissue samples were subjected to histopathology and staining. The lung tissues of the animals had diffuse congestion and subpleural petechial hemorrhages. In addition, small nodules of varied diameters were seen scattered on the lung lobes of both animals. On histopathological examination, the lung tissue of one of the animals showed extensive proliferation of blood vessels. Congestion and subpleural hemorrhages were seen in both cases. Few macrophages and epithelioid cells were seen scattered adjacent to a bronchiole. Kinyoun's acid fast staining of the histological sections revealed numerous acid fast bacilli indicative of tuberculosis.
\end{abstract}

Key words: Tuberculosis, sloth bear, post-mortem

Sloth bear (Melursus ursinus) is one of the four species of bears which are found in India. They are classified as vulnerable species according to the International Union for Conservation of Nature and included in schedule I of the Indian Wildlife Protection Act, 1972. Tuberculosis (TB), caused by Mycobacterium tuberculosis is a significant cause of morbidity and mortality in both wild

${ }^{*}$ Part of M.V.Sc. thesis research work of the first author to Kerala Veterinary and Animal Sciences University, Pookode, Wayanad, Kerala

1. M.V.Sc. scholar (Email gowrimenon94@gmail.com Phone 8098746456)

2. Assistant Professor and corresponding author, Email: kcbipin@gmail.com, Phone: 9447153448

3. Assistant Professor and Head i/c

4. Assistant Professor

5. Assistant Professor, Dept. of Veterinary Pathology

6. Director, Research \& Veterinary Operations, Bannerghatta Bear Rescue Centre, Bengaluru

Copyright: ( 2021 N. Gowri Menon et al. This is an open access article distributed under the terms of the Creative Commons Attribution 4.0 International License (http://creativecommons.org/licenses/by/4.0/), which permits unrestricted use, distribution, and reproduction in any medium, provided the original author and source are credited. 
and domestic animals worldwide (Lecu and Ball, 2011). Emergence of tuberculosis in sloth bears could be due to the spillover of Mycobacterium tuberculosis into this species because of their prolonged contact with humans. A significant number of sloth bears were poached by a community of people known as the Kalandars, and trained for street shows. There is inadequacy of diagnostic assays for detecting tuberculosis in these animals. Moreover, the affected bears appear apparently healthy and exhibit only mild or vague clinical signs in the terminal stages, which make diagnosis and treatment difficult. Hence diagnosis of tuberculosis in this species during post-mortem examination is important for considering preventive measures in live animals against TB.

\section{Materials and methods}

Two sloth bears, which died naturally at Bannerghatta Bear Rescue Centre, formed the sample of the study. Both the bears exhibited anorexia, isolation from the group and considerable weight loss before death. A thorough post-mortem examination of the animals was carried out and representative samples from lungs were collected in 10 per cent neutral buffered formalin for histopathology.

The formalin fixed samples were washed overnight, processed, cut at five micron thickness and stained with haematoxylin and eosin as per Suvarna et al., 2012. Special staining technique, Kinyoun's acid fast staining, was done to demonstrate the presence of the acid fast bacteria. The staining procedure is briefed below.

The tissue sections were deparaffinized and hydrated to distilled water after which it was immersed in Kinyoun's carbol fuchsin and incubated at $50^{\circ} \mathrm{C}$ for one hour. The slides were differentiated in two changes of one per cent acid alcohol after washing in running tap water. Counterstaining was done using methylene blue solution and the slides were dehydrated in 95 and 100 per cent alcohol sequentially and cleared in two changes of xylene. The stained sections, after drying completely, were mounted in DPX and viewed under oil immersion objective (100x) in a compound microscope.
Fluorescent staining technique using auramine was also performed to further confirm the presence of acid fast bacilli. Staining technique was done as per Suvarna et al., 2012 with slight modifications. The tissue sections were deparaffinized and hydrated to distilled water after which the slides were flooded with phenolic auramine $-\mathrm{O}$ and placed at $60^{\circ} \mathrm{C}$ for 10 minutes. It was then rinsed off with distilled water and decolourised using one per cent acid alcohol for 2 minutes. Counterstaining was done using Potassium permanganate solution for five minutes. The slides were then dehydrated in 95 and 100 per cent alcohol sequentially and cleared in two changes of xylene. The stained sections, after drying completely, were mounted in DPX and viewed under oil immersion objective (100X) of fluorescent microscope $\left(\right.$ Carl Ziess $\left.{ }^{\circledR}\right)$.

\section{Results and discussion}

On gross examination, the carcasses of both the animals appeared emaciated. Diffuse congestion along with subpleural petechial hemorrhages were evident in all lung lobes of the first animal (Fig. 1). This finding is in agreement with Pereira (2016) who also reported presence of areas of congestion and hemorrhage as post-mortem findings in TB affected sloth bears. Small nodules of two centimeter diameter were seen scattered on both lung lobes. The right cranial lobe showed two distinct dark red colored nodules of three to four centimeter diameter. This is in agreement with Hedau and Kamdi (2016) who reported the same in a sloth bear carcass suspected to have died of TB.

The second animal showed multiple nodules of two to three centimeter diameter scattered over the parenchyma of both left and right lung lobes (Fig. 2). In addition, left lung lobes had diffuse areas of congestion and mild edema. The present findings are in agreement with Hunter (2011) who reported that granulomas were characteristic lesions of primary TB in immune-competent individuals.

Microscopically, extensive proliferation of capillaries along with severe congestion and hemorrhages were found in the lung tissue sample of the first animal, suggestive 


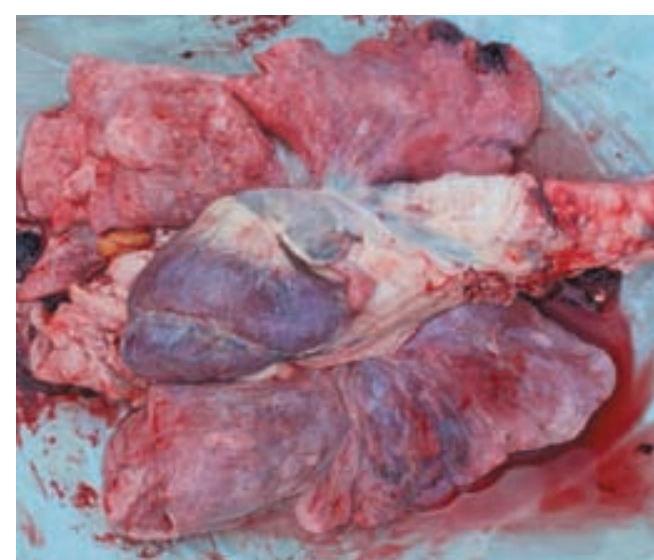

Fig. 1. Gross picture showing diffuse congestion and subpleural petechial haemorrhages in lung tissue

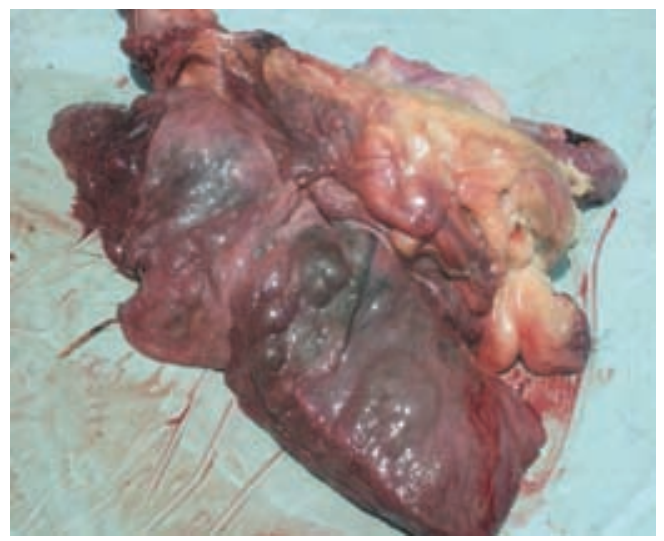

Fig. 2. Gross picture showing multiple nodular lesions in lung

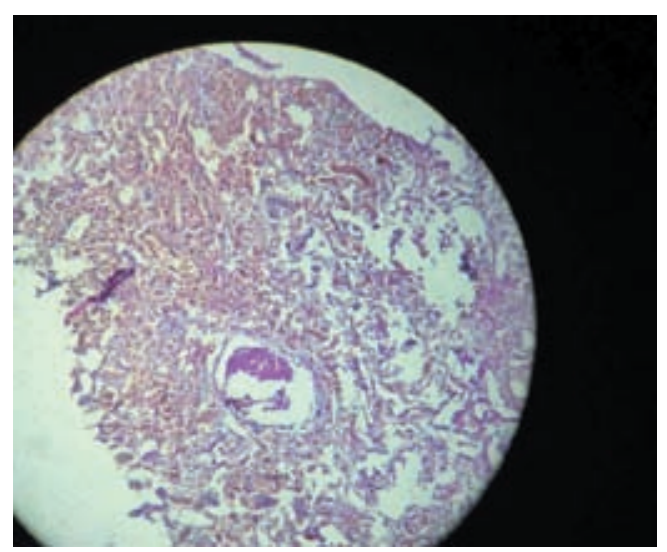

Fig. 3. Capillary proliferation with congestion and haemorrhage, $\mathrm{H}$ and $\mathrm{E}(100 \mathrm{x})$

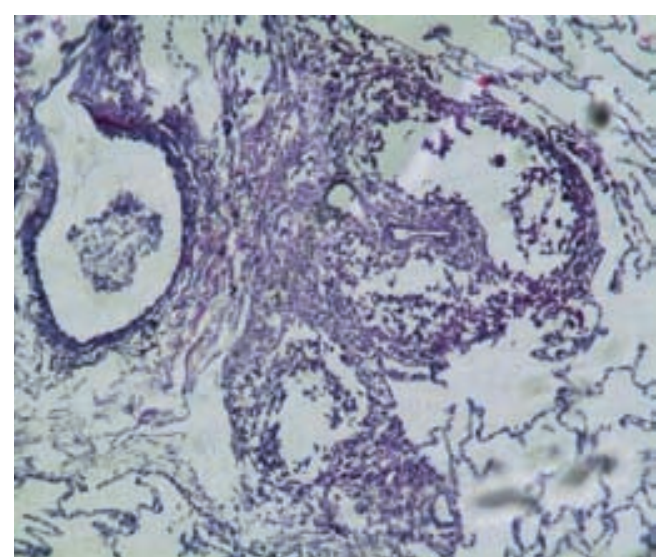

Fig. 4. Lung section with macrophages and epithelioid cells scattered adjacent to bronchiole, $\mathrm{H}$ and $\mathrm{E}$ (100x)

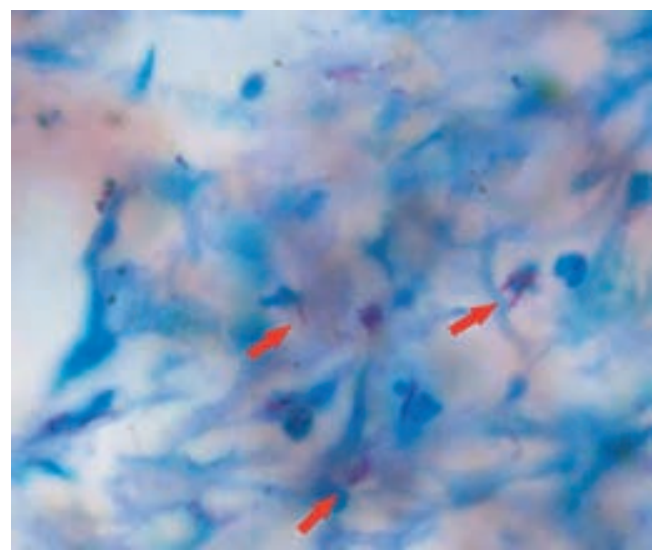

Fig. 5. Lung tissue with acid fast bacilli (arrow), Kinyoun's acid fast staining (1000x)



Fig. 6. Lung tissue with acid fast bacilli (arrow), Fluorescent staining (1000x) 
of haemangioma (Fig. 3), whereas the lung tissue sample from second animal showed focal areas of macrophages and epithelioid cell proliferation adjacent to a bronchiole (Fig. 4). The typical tubercular granuloma with central caseous necrosis and surrounding inflammatory cells as described by Fefar et al. (2012) was not present in both the samples. However, Hernandez-Pando et al. (2000) had reported the presence of $M$. tuberculosis in lungs without typical histopathologic lesions of TB in case of human beings.

Both the tissue sections showed the presence of numerous acid fast bacilli when stained using Kinyoun's acid fast staining technique (Fig. 5). This is in agreement with Stephenson and Byard (2020) who reported that TB could be confirmed histologically by acid fast staining of suspected tissue sections. Rishikesavan et al. (2010) also confirmed TB in a captive male leopard by the presence of numerous acid fast bacilli in stained tissue impression smears.

Fluorescent staining for mycobacteria was also carried out in the tissue sections and both tissue samples showed the presence of numerous fluorescent acid fast bacilli when viewed under oil immersion objective (100X) of fluorescent microscope (Fig. 6). This is in agreement with Bodal et al. (2015) who reported that fluorescent staining was highly sensitive and can be used to confirm TB.

In the present study, both acid fast and fluorescent staining of histological sections showed identical results, which indicate that both these techniques are equally effective in confirming TB in post mortem samples. However, Kommareddi et al. (1984) reported that fluorescent staining using Auramine- 0 was simpler and had more sensitivity compared to Ziehl Neelsen (ZN) technique, at the same time, less specific than $\mathrm{ZN}$ technique.

\section{Acknowledgement}

The authors would like to acknowledge Karnataka Forest Department, Wildlife SOS, Bannerghatta Bear Rescue Centre and Kerala Veterinary and Animal Sciences University for their support.

\section{References}

Bodal, V.K., Bal, M.S., Bhagat, S., Kishan, J. and Brar, R.K., 2015. Fluorescent microscopy and Ziehl-Neelsen staining of bronchoalveolar lavage, bronchial washings, bronchoscopic brushing and post bronchoscopic sputum along with cytological examination in cases of suspected tuberculosis. Indian J. Pathol. Microbiol. 58: 443.

Fefar, D.T., Jivani, B.M., Mathukiya, R.A., Undhad, V.V., Ghodasara, D.J., Josh, B.P., Dave, C.J. and Prajapati, K.S., 2012. A case report of tuberculosis in a captive sloth bear (Melursus ursinus). Zoos' Print. 25: 28-29.

Hedau, M. and Kamdi, B.P., 2016. Tuberculosis in captive sloth bear (Melursus ursinus). Int. J. Scient. Res. Mgmt. 4: 4941-4943.

Hernandez-Pando, R., Jeyanathan, M., Mengistu, G., Aguilar, D., Orozco, H., Harboe, M., Rook, G.A.W. and Bjune, G., 2000. Persistence of DNA from Mycobacterium tuberculosis in superficially normal lung tissue during latent infection. The Lancet, 356: 21332138.

Hunter, R.L., 2011. Pathology of post primary tuberculosis of the lung: an illustrated critical review. Tuberculosis. 91: 497509.

Kommareddi, S., Abramowsky, C.R., Swinehart, G.L. and Hrabak, L., 1984. Nontuberculous mycobacterial infections: comparison of the fluorescent auramine-O and Ziehl-Neelsen techniques in tissue diagnosis. Hum. Path. 15: 1085-1089.

Lécu, A. and Ball, R., 2011. Mycobacterial infections in zoo animals: relevance, diagnosis and management. Int. Zoo Yb. 45: 183-202.

Pereira, M.I.R. 2016. Tuberculosis infection in captive sloth bears (Melursus ursinus): 
a pilot study on diagnostic strategies. Ph.D. thesis, University of Lisbon, 28p.

Rishikesavan, R., Chandranaik, B.M., Bamne, S., Satish, R., Giridhar, P. and Renukaprasad, C. 2010. Patho epidemiological study of tuberculosis in Panthera pardus. Zoos'Print. 25: 28-29.

Stephenson, L. and Byard, R.W., 2020. An atlas overview of characteristic features of tuberculosis that may be encountered at autopsy. Forensic Sci. Med. Path. 16: 143-151.

Suvarna, S.K., Layton, C. and Bancroft, J.D. 2012. Bancroft's theory and practice of histological techniques ( $7^{\text {th }} \mathrm{Ed}$.). Churchill Livingstone Elsevier, Philadelphia. 654p. 